\title{
Disclosure, Multiple Sex Partners, and Consistent Condom Use among HIV Positive Adults on Antiretroviral Therapy in Johannesburg, South Africa
}

\author{
Sphiwe Madiba, Beverley Letsoalo \\ Department of Environmental and Occupational Health, School of Public Health, Faculty of Health Sciences, \\ University of Limpopo, Medunsa Campus, Mankweng, South Africa \\ Email: sphiwe madiba@embanet.com
}

Received 25 September 2013; revised 25 October 2013; accepted 1 November 2013

Copyright (C) 2014 by authors and Scientific Research Publishing Inc.

This work is licensed under the Creative Commons Attribution International License (CC BY). http://creativecommons.org/licenses/by/4.0/

c) (i) Open Access

\begin{abstract}
Inconsistent condom use among persons on antiretroviral treatment (ART) is a major public health concern because of the risk of HIV transmission. This study examined the association between socio-demographic variables and knowing partners' HIV status, multiple sex partners, and consistent condom use among $400 \mathrm{HIV}$-infected adults who had received ART for at least six months in Johannesburg, South Africa. The study used a cross-sectional survey and a structured interviewer administered questionnaire. Over half $(n=225,56.3 \%)$ of participants were on ART for more than two years. Two thirds $(n=234,63.2 \%)$ were aware of partner's HIV status. Over a third $(n=136,34.0 \%)$ reported having more than one sex partners. Three quarters $(n=279$, $75.8 \%$ ) reported consistent condom use with regular partner. Discussing HIV testing (aOR $=2.28$, CI: 1.31 - 3.95), awareness of partner's HIV status (aOR $=2.59$, CI: $1.50-4.46)$, level of education ( $\mathrm{OOR}=0.64$, CI: $0.42-0.98$ ), and duration on ART ( $\mathrm{OOR}=0.71, \mathrm{CI}: 1.31-3.95$ ) were predictors for consistent condom use. Awareness of partner's HIV status was associated with multiple partnership (aOR $=0.38, \mathrm{CI}: 0.21-0.66)$, living with partner $(\mathrm{aOR}=4.75, \mathrm{CI}: 2.86-7.91)$, discussing HIV testing ( $\mathrm{aOR}=2.43$, CI: 1.48 - 3.99), and duration on ART (aOR $=2.04, \mathrm{CI}: 1.43-2.92)$. While gender ( $\mathrm{OOR}=5.68, \mathrm{CI}$ : 3.46 - 9.34), marital status $(\mathrm{aOR}=0.44, \mathrm{CI}$ : $0.25-0.77)$, and awareness of partner's HIV status (aOR $=0.52$, CI: $0.30-0.89$ ) were associated with multiple partnerships. Risky sexual behaviours occurred in all types of partners and knowing partner's HIV status was a predictor for consistent condom use with all types of partners. It is essential that HIV prevention strategies create an enabling environment for disclosure and reductions of risky sexual behaviours by HIV-infected persons on ART.
\end{abstract}




\section{Keywords}

\section{Sexual Risk Behaviour; Condom Use; ART; South Africa; Partner's Status; Multiple Partnerships; HIV Testing}

\section{Introduction}

The practice of consistent condom use and sexual risk practice among HIV positive persons have not received attention as among people uninfected with HIV. This is because HIV programs focus prevention efforts largely on people uninfected with HIV [1] [2]. The findings of the few studies that have examined condom use among HIV-infected persons receiving antiretroviral treatment (ART) vary considerably, and there is no consensus on the predictors of consistent condom use. In addition, there is a dearth of studies that examine whether initial decreases in sexual risk behavior among HIV-infected persons on ART are sustained and reasons for this [3]. However, there is an evidence that engaging in unprotected sex with HIV positive individuals is high risk sexual behaviour for HIV transmission and a major public health problem [4] [5].

Several studies have shown that access to ART has not led to significant reductions in risky sexual behavior among HIV-infected persons [2] [3] [6]. Moreover, there are concerns that providing ART may lead to an increase in sexual risk behaviours because of the improved quality of life associated with ART [1] [7]. On the other hand, there is evidence that HIV-infected persons on ART adopt safer sex practices to avoid HIV transmission to their sex partners. Data from South Africa, Ethiopia, and Uganda, and Kenya revealed that sexual risk behaviors declined significantly after ART initiation. A higher proportion of HIV-infected persons on ART reported consistent condoms use with regular partners compared with those not receiving ART [1]-[3] [7]-[10].

It should be noted that although studies report reductions in risky sexual behaviour among HIV-infected persons, none have reported a hundred percent consistent condom use among their participants. This suggests rates of considerable levels of unprotect sex among HIV-infected persons on ART. According to Kay [11], reductions in high risk sexual behavior among HIV-infected persons have been inconsistent over time, with some studies indicating an increase and others a reduction in high-risk behaviors following ART initiation. Studies conducted in Tanzania and Kenya found low rates of consistent condom use among HIV-infected persons on ART [12] [13]. While findings from India, Ethiopia, and Uganda revealed that although a high proportion of HIV-infected persons on ART used condoms consistently, up to one third continue to practice unprotected sex [2] [8] [14].

Of public health concern, is the reported inconsistent condom use by HIV-infected persons regardless of the HIV status of the partner. Wagner et al. [15] found that 50\% - 70\% of seroconcordant, serodiscordant, and unknown status couples reported unprotected sex with their partners. Not disclosing one's HIV status to a sexual partner increases the risk of having unprotected sex among HIV-infected persons on ART [7] [16] [17]. Knowledge of partner's HIV status contributes to an increase in condom use among HIV-infected persons, which subsequently reduces HIV infection [12] [15] [18] [19].

South Africa has the largest ART program in the world and yet there is a dearth of studies on the practice of condom use among ART patients. This is despite evidence showing that a concerning proportion of HIV-infected persons on ART engage in unprotected sex [2] [3] [12] [13] [15]. Although the focus of the studies that were conducted was on the impact of ART on consistent condom use, other variables associated with consistent condom use are also under researched and vary across studies. An understanding of the dynamics that contribute to high sexual risk behavior among HIV-infected persons will inform the development of effective interventions for safe sexual practices [15]. This study examined the association between socio-demographic variables and knowing partners' HIV status, multiple sex partners, and consistent condom use among HIV positive adults on ART in a clinic in Johannesburg, South Africa.

\section{Methods and Materials}

\subsection{Study Design}

A cross-sectional survey was conducted among adult patients attending an ART clinic attached to a tertiary hospital from October to November 2012. The hospital is located in the City of Johannesburg in Gauteng province, 
South Africa and serves patients across the suburbs, informal settlements, and the central business centre. The study participants were adult patients who had received ART for six months and above. All male and female patients above 18 years of age who met the inclusion criteria were eligible to participate in the study. Participants were recruited as they came for follow-up services. The sample size was calculated at 400 using the single population formula at 95\% Confidence Interval (CI).

\subsection{Data Collection}

The second author and a trained research assistant conducted face to face interviews using pretested structured questionnaires. The questionnaire was first prepared in English and translated into Setswana and IsiZulu. Besides English, these are the two languages commonly spoken across the province.

The main outcome variable for the study was consistent condom use within the past three months. Consistent condom use was defined as "always using condoms" and was measured as consistent if participants reported that they always used condoms. Inconsistent condom use was defined as never used condoms and used condoms sometimes. Secondary outcomes for the study were; awareness of partner's HIV status and having multiple sex partners. Knowledge of partner's HIV status refers to the participant's awareness or unawareness of their partner's HIV status. Multiple sex partners were defined as having two or more sex partners.

The independent variables included socio demographic, sexual behaviour, and HIV related variables. Sociodemographic data included age, gender, level of education, marital status, and employment status. Sexual behaviour data included the number of sex partners and types of sexual partners. In this study, a steady partner referred to a partner with whom the participant had a regular sexual relationship and who was perceived to be the spouse or regular boy/girlfriend. A casual partner referred to a partner with whom the participant had sex infrequently and was not living with or married to. HIV/AIDS related data include time since diagnosis with HIV, duration of ART, knowledge of partner's HIV status and discussing HIV testing with partner.

\subsection{Ethics}

Study participants provided a written informed consent prior to the interview. Ethical approval for the study was obtained from the Research Ethics Committee of the University of Limpopo. Permission to conduct the study was granted by the Hospital management. Participation in the study was voluntary, and the researchers ensured confidentiality throughout data collection.

\subsection{Data Analysis}

The statistical analyses were done using the Stata version 10 statistical software [20]. Following the descriptive analysis, bivariate analyses were performed to assess the association between consistent condom use, multiple sex partners, and awareness of partner's HIV status and the independent variables. Multiple logistic regression analyses were performed to determine predictors of consistent condom use, multiple sex partners, and awareness of partner's status. During the stepwise modeling, all variables found to be statistically significant with a value of $\mathrm{p}<0.05$ were included in multivariate models. We presented the results as unadjusted odds ratios (cOR) and adjusted odds ratios (aOR) with 95\% confidence interval (CI).

\section{Results}

\subsection{Socio Demographic Characteristics of Participants}

The total sample included 400 HIV positive ART patients with a mean age of 39.8 years (IQR $=19$ - 69). Two thirds ( $n=244,61.0 \%)$ were below 40 years whilst the rest $(n=156,39.0 \%)$ were above 40 years. Participants in the 40 years and above age group were two times more likely to use condoms in a consistent manner $(\mathrm{OR}=1.95$, CI: 1.13 - 3.34, $p=0.015)$ than those who were younger than 40 years. More than half $(n=229,57.3 \%)$ were females and $(\mathrm{n}=171,42.8 \%)$ were males. Gender was not statistically associated with consistent condom use.

Over half $(n=211,52.8 \%)$ were single, $(n=106,26.5 \%)$ were married, and the rest were cohabiting, divorced, and widowed. Participants who were ever married were two times more likely to use condoms consistently (OR $=2.01$, CI: $1.18-3.42, \mathrm{p}=0.010)$ than those who were never married.

Over half $(n=237,59.3 \%)$ had a secondary education and $(n=95,23.8 \%)$ had a tertiary education. Partici- 
pants with a college or tertiary education had a significantly decreased odds of using condoms in an inconsistent manner $(\mathrm{OR}=0.36$, CI: $0.15-0.83, \mathrm{p}=0.018)$ than those with a secondary and primary education. Two thirds $(n=250,62.7 \%)$ were employed, and employment status was not statistically associated with consistent condom use (Table 1).

\subsection{HIV Related Characteristics}

With regards to time since diagnosis, over half $(\mathrm{n}=223,55.8 \%)$ had known about their HIV status for 1 - 5 years, $(\mathrm{n}=177,44.3 \%)$ for more than 5 years, the mean time since diagnosis was 5.88 years $(\mathrm{IQR}=1-20)$. A high proportion $(n=225,56.3 \%)$ had been on ART for more two years, $(n=105,26.3 \%)$ for less than one year, and $(\mathrm{n}=70,17.5 \%)$ for one year.

With regards to awareness of partner's HIV status, two thirds $(n=234,63.2 \%)$ were aware of the HIV status of their regular partners.

About a quarter $(n=53,22.7 \%)$ of participants who were aware of their partners' HIV status indicated that their partners were HIV negative, and $(n=181,77.4 \%)$ indicated that their partners were HIV positive. Partner status was not statistically associated with consistent condom use.

Over half $(n=209,52.3 \%)$ of participants indicated that they discussed HIV testing with their regular sex

Table 1. Bivariate analysis of socio-demographic factors associated with consistent condom use among ART patients in Johannesburg, South Africa.

\begin{tabular}{|c|c|c|c|c|}
\hline & \multirow[t]{2}{*}{ ALL } & \multicolumn{2}{|c|}{ Consistent condom use } & \multirow[t]{2}{*}{ ORs \& 95\% CI } \\
\hline & & No & Yes & \\
\hline Female & $205(55.7)$ & $44(49.4)$ & $161(57.7)$ & $0.71(0.44-1.15)$ \\
\hline Male & $163(44.2)$ & 45 (50.6) & $118(42.3)$ & \\
\hline \multicolumn{5}{|l|}{ Age } \\
\hline$>40$ years & $237(64.4)$ & $67(75.3)$ & $170(60.9)$ & $1.04(1.01-1.06)$ \\
\hline$\leq 40$ years & $131(35.6)$ & $22(24.7)$ & 109 (39.1) & \\
\hline \multicolumn{5}{|c|}{ Employment status } \\
\hline Scholar & $7(1.9)$ & 0 & $7(2.5)$ & $0.80(0.50-1.29)$ \\
\hline Unemployed & $123(33.5)$ & $29(33.0)$ & $94(33.7)$ & \\
\hline Employed & $237(64.6)$ & $59(67.0)$ & $178(63.8)$ & \\
\hline \multicolumn{5}{|c|}{ Educational status } \\
\hline Primary & 61(16.6) & $9(10.1)$ & $52(18.6)$ & $0.36(0.15-0.83)$ \\
\hline Secondary & $217(59.0)$ & $51(57.3)$ & $166(59.5)$ & \\
\hline Tertiary & $90(24.4)$ & 29 (32.6) & $61(21.9)$ & \\
\hline \multicolumn{5}{|c|}{ Marital status } \\
\hline Single & $263(71.5)$ & $76(85.4)$ & $187(67.0)$ & $2.01(1.18-3.42)$ \\
\hline Ever married & $105(28.5)$ & $13(14.6)$ & $92(33.0)$ & \\
\hline \multicolumn{5}{|c|}{ Type of partner } \\
\hline Casual & $93(25.3)$ & $29(32.6)$ & 64 (22.9) & $3.34(1.61-6.92)$ \\
\hline Steady & $275 \quad(74.7)$ & $60(67.4)$ & $215(77.1)$ & \\
\hline \multicolumn{5}{|c|}{ Living with sex partner } \\
\hline No & $182(49.5)$ & $50(56.2)$ & $132(47.3)$ & $1.90(1.25-2.88)$ \\
\hline Yes & $186(50.5)$ & 39 (43.8) & $147(52.7)$ & \\
\hline \multicolumn{5}{|c|}{ Number of sex partners } \\
\hline One partner & $232(63.0)$ & $46(51.7)$ & $186(66.7)$ & $0.52(0.32-0.85)$ \\
\hline Multiple & $136(37.0)$ & $43(48.3)$ & 93 (33.3) & \\
\hline
\end{tabular}

* OR: odds ratios, CI: Confidence interval. 
partners prior to testing. Participants who discussed HIV testing were three times more likely to use condoms consistently (OR $=3.29$, CI: $1.98-5.47, \mathrm{p}<0.000)$ as compared to those who did not (Table 2).

\subsection{Sexual Practices and Partner's Related Characteristics}

Of the 400 participants who participated in the surveys, $(n=360,90 \%)$ were sexually active in the 3 months before the survey, whilst $(\mathrm{n}=30,7.5 \%)$ had no sex partners. In terms of the number of sex partners, over half ( $\mathrm{n}$ $=234,58.5 \%)$ indicated having one sex partner, more than a third $(n=136,34.0 \%)$ had more than one sex partners, and $(n=30,7.5 \%)$ had no sex partners during that time. More men $(n=91,55.8 \%)$ than women $(n=72$, 44.2\%) had more than on sex partners.

Of the 234 participants who reported a single partnership, $(\mathrm{n}=103,44.1 \%)$ identified that person as a steady partner, $(n=83,35.5 \%)$ identified that person as a spouse, and $(n=48,20.5 \%)$ as a casual partner. Of the 136 participants who reported multiple sex partners, $(n=63,46.3 \%)$ identified their regular partner as a steady partner, $(n=46,33.8 \%)$ as a casual partner, and $(n=27,19.9 \%)$ as a spouse. An equal proportion $(n=185,50 \%)$ of the sexually active participants were living with sex partners and alone respectively. Participants who were living with their sex partners were two times more likely to use condoms in a consistent manner $(\mathrm{OR}=1.90$, CI: $1.25-2.88, \mathrm{p}=0.002$ ) than those living alone (Table 1).

\subsection{Consistent Condom Use}

Three quarters $(\mathrm{n}=279,75.8 \%)$ of participants reported that they used condoms in a consistent manner while (n $=89,22.4 \%$ ) had used condoms inconsistently. Of the 89 respondents who used condoms in an inconsistent manner, $(\mathrm{n}=60,67.4 \%)$ were with a steady partner, $(\mathrm{n}=29,32.6 \%)$ with a casual partner. In multivariate analysis, we found that level of education (aOR $=0.63$, CI: $0.41-0.98, \mathrm{p}=0.041$ ), discussing HIV testing with sex

Table 2. Bivariate analysis of HIV related factors associated with consistent condom use among ART patients in Johannesburg, South Africa.

\begin{tabular}{|c|c|c|c|c|}
\hline & ALL & \multicolumn{2}{|c|}{ Consistent condom use } & Odds ratio/Confidence interval \\
\hline & No & Yes & & \\
\hline \multicolumn{5}{|c|}{ Discussing HIV test with partner } \\
\hline No & $173(47.0)$ & $61(68.5)$ & $112(40.1)$ & $3.29(1.98-5.47)$ \\
\hline Yes & $195(53.0)$ & $28(31.5)$ & 167 (59.9) & \\
\hline \multicolumn{5}{|c|}{ Time since diagnosis } \\
\hline 1 - 5 years & $215(58.4)$ & 68 76.4) & $147(52.7)$ & $3.71(2.11-6.53)$ \\
\hline$>5$ years & $153(41.6)$ & $21(23.6)$ & $132(47.3)$ & \\
\hline \multicolumn{5}{|l|}{ Duration of ART } \\
\hline$>1$ year & $102(27.7)$ & 39 (43.8) & $63(22.6)$ & $2.90(1.68-5.00)$ \\
\hline 1 year & $70(19.0)$ & $22(24.7)$ & $48(17.2)$ & \\
\hline$\leq 2$ years & $196(53.3)$ & $28(31.5)$ & $168(60.2)$ & \\
\hline \multicolumn{5}{|c|}{ Know regular sex partners' status } \\
\hline Unaware & 135 (36.7) & $55(61.8)$ & $80(28.7)$ & $4.09(2.48-6.75)$ \\
\hline Aware & $233(63.3)$ & $34(38.2)$ & $199(71.3)$ & \\
\hline \multicolumn{5}{|c|}{ HIV status of regular sex partner } \\
\hline Negative & $53(22.6)$ & $5(14.7)$ & $48(24.1)$ & $0.54(0.20-1.48)$ \\
\hline Positive & $180(77.3)$ & 29 (85.3) & $151(75.9)$ & \\
\hline \multicolumn{5}{|c|}{ Disclosed HIV status to regular partner } \\
\hline No & 89 (24.5) & 49 (58.3) & 40 (14.3) & $8.61(4.96-14.9)$ \\
\hline Yes & $274(75.5)$ & 35 (41.7) & $239(85.7)$ & \\
\hline
\end{tabular}


partner (aOR = 2.36, CI: $1.35-4.15, \mathrm{p}=0.003)$, duration on ART (aOR = 1.69, CI: $1.15-2.45, \mathrm{p}=0.007)$, and awareness of partner's HIV status $(\mathrm{aOR}=2.91$, CI: $2.911 .57-5.37, \mathrm{p}=0.001)$, were statistically associated with consistent condom use (Table 3).

Variables associated with consistent condom use that showed statistical significance $(p<0.05)$ in bivariate analyses were considered for multiple logistic regressions. The stepwise logistic regression revealed that discussing HIV testing with partner ( $\mathrm{aOR}=2.28$, CI: $1.31-3.95, \mathrm{p}=0.003$ ), awareness of partner's HIV status (aOR $=2.59$, CI: $1.50-4.46, \mathrm{p}=0.001)$, duration on ART (aOR = 0.71, CI; $1.31-3.95, \mathrm{p}<0.001$ ), and educational level $(\mathrm{aOR}=0.64$, CI: $0.42-0.98, \mathrm{p}=0.043)$ are factors independently associated with consistent condom use.

\subsection{Awareness of Partner's HIV Status}

With regards to awareness of partner's HIV status, $(n=234,63.2 \%)$ participants were aware of their regular partner's HIV status. Participants who were aware of their partner's HIV status were four times more likely to use condoms in a consistent manner ( $\mathrm{OR}=4.09$, CI: 2.48-6.75, $\mathrm{p}<0.001$ ) that those who were not. With all the independent variables entered simultaneously, we found that knowing partner's HIV status was associated with marital status (aOR $=2.03$, CI: $1.07-3.85, \mathrm{p}=0.028)$, living with partner $(\mathrm{aOR}=3.06$, CI: $1.69-5.54, \mathrm{p}<$ 0.001 ), number of sex partners ( $\mathrm{aOR}=0.46$, CI: $0.26-0.81, \mathrm{p}=0.008$ ), discussing HIV testing with partner $(\mathrm{aOR}=2.25$, CI: $1.36-3.74, \mathrm{p}=0.002)$, and time since diagnosis $(\mathrm{OR}=2.54$, CI: $1.31-4.91, \mathrm{p}=0.006)($ Table 4).

The stepwise logistic regression revealed that marital status ( $\mathrm{aOR}=1.97$, CI: $1.05-3.72, \mathrm{p}=0.035$ ), number of sex partners (aOR $=0.50$, CI; $0.30-0.83, \mathrm{p}=0.008)$, living with partner $(\mathrm{aOR}=3.58$, CI: $2.08-6.17, \mathrm{p}<$ $0.001)$, discussing HIV testing with partner $(\mathrm{aOR}=2.24$, CI; $1.35-3.70, \mathrm{p}=0.002)$, and time since diagnosis $(\mathrm{aOR}=2.51, \mathrm{CI} ; 1.44-4.38, \mathrm{p}=0.001)$ remained significantly associated with awareness of partners HIV status.

\subsection{Multiple Sex Partners}

A third ( $n=136,34.0 \%$ ) of the participants had more than one sex partners. We found that gender, marital status, awareness of partner's HIV status, and type of partner were statistically associated with the tendency to engage in multiple partnerships. Men were 5.7 times more likely to have more than one partner (aOR $=5.69$, CI: 3.39 9.57, $\mathrm{p}<0.001)$ compared to women. Participants who were married had a significantly decreased odds of engaging in multiple partnership ( $\mathrm{aOR}=0.43$, CI: $0.24-0.75, \mathrm{p}=0.003$ ) than those who were never married. Participants who were aware of their partners' HIV status had a significantly decreased odds of engaging in multiple partnership ( $\mathrm{aOR}=0.46$, CI; $0.24-0.86, \mathrm{p}=0.016$ ) compared to those who were not aware of partners' HIV status. Participants who were in a steady relationship had a significantly decreased odd of engaging in

Table 3. HIV testing with sex partner.

\begin{tabular}{ccc}
\hline & Unadjusted Odds Ratios & Adjusted Odds ratios \\
\hline Age of participants & OR/95\% CI & OR/95\% CI \\
Educational status & $1.04(1.01-1.06)$ & $1.17(0.61-2.22)$ \\
Marital status (married vs single) & $0.36(0.15-0.83)$ & $0.63(0.41-0.98)$ \\
Type of partner (casual vs steady) & $2.01(1.18-3.42)$ & $1.15(0.58-2.26)$ \\
Living with sex partner (yes vs no) & $3.34(1.61-6.92)$ & $1.18(0.61-2.27)$ \\
Number of sex partners (one vs multiple) & $1.90(1.25-2.88)$ & $0.64(0.32-1.26)$ \\
Discussed HIV testing with partner(yes vs no) & $0.52(0.32-0.85)$ & $0.79(0.43-1.45)$ \\
Time since diagnosis (<5 years vs $>5$ years & $3.29(1.98-5.47)$ & $2.36(1.35-4.15)$ \\
Duration of ART & $3.71(2.11-6.53)$ & $1.01(0.47-2.13)$ \\
Know regular partner’s status (aware vs unaware) & $2.90(1.68-5.00)$ & $1.68(1.15-2.45)$ \\
\hline
\end{tabular}


Table 4. Partners’ HIV status.

\begin{tabular}{|c|c|c|c|c|}
\hline & \multicolumn{2}{|c|}{ Awareness of partner's HIV status } & \multirow{2}{*}{$\begin{array}{c}\text { Adjusted Odds ratios } \\
\text { OR/95\% CI }\end{array}$} & \multirow[t]{2}{*}{ p value } \\
\hline & Unaware & Aware & & \\
\hline \multicolumn{5}{|l|}{ Age } \\
\hline$<40$ years & $104(76.5)$ & $133(56.8)$ & $1.02(0.98-1.05)$ & 0.231 \\
\hline$\geq 40$ years & $32(23.5)$ & $101(43.2)$ & & \\
\hline \multicolumn{5}{|l|}{ Gender } \\
\hline Female & $81(59.6)$ & $126(53.9)$ & $1.33(0.75-2.39)$ & 0.322 \\
\hline Male & $55(40.4)$ & $108(46.2)$ & & \\
\hline \multicolumn{5}{|c|}{ Educational status } \\
\hline Primary & $15(11.0)$ & $48(20.5)$ & $0.89(0.58-1.36)$ & 0.605 \\
\hline Secondary & $85(62.5)$ & $132(56.4)$ & & \\
\hline Tertiary & $36(26.5)$ & $54(23.1)$ & & \\
\hline \multicolumn{5}{|l|}{ Marital status } \\
\hline Single & $114(83.8)$ & $116(49.6)$ & $2.03(1.07-3.85)$ & 0.028 \\
\hline Married & $22(16.2)$ & $118(50.4)$ & & \\
\hline \multicolumn{5}{|c|}{ Living with sex partner } \\
\hline No & $102(75.0)$ & $82(35.0)$ & $3.06(1.69-5.54)$ & 0.000 \\
\hline Yes & $34(25.0)$ & $152(65.0)$ & & \\
\hline \multicolumn{5}{|l|}{ Type of partner } \\
\hline Casual & $56(41.2)$ & $38(16.2)$ & $3.03(2.18-4.20)$ & 0.001 \\
\hline Steady & $80(58.8)$ & $196(83.8)$ & & \\
\hline \multicolumn{5}{|c|}{ Number of sex partners } \\
\hline One & $71(52.2)$ & $163(69.7)$ & $0.46(0.26-0.81)$ & 0.008 \\
\hline Multiple & $65(47.8)$ & $71(30.3)$ & & \\
\hline \multicolumn{5}{|c|}{ Discuss HIV testing with partner } \\
\hline No & $89(65.4)$ & $85(36.3)$ & $2.25(1.36-3.74)$ & 0.002 \\
\hline Yes & $47(34.6)$ & $149(63.7)$ & & \\
\hline \multicolumn{5}{|c|}{ Time since diagnosis } \\
\hline 1 - 5 years & $103(75.7)$ & $113(48.3)$ & $2.54(1.31-4.91)$ & 0.006 \\
\hline$>5$ years & $33(24.3)$ & $121(51.7)$ & & \\
\hline \multicolumn{5}{|l|}{ Duration of ART } \\
\hline$>1$ year & $51(37.5)$ & $51(21.8)$ & $1.00(0.70-1.43)$ & 0.984 \\
\hline 1 year & $28(20.6)$ & $42(18.0)$ & & \\
\hline$\leq 2$ years & 57 (41.9) & $141(60.2)$ & & \\
\hline
\end{tabular}

multiple partnership ( $\mathrm{aOR}=0.50$, CI; $0.31-0.81, \mathrm{p}=0.005)$.

The stepwise logistic regression revealed that gender $(\mathrm{aOR}=5.68, \mathrm{CI} ; 3.46-9.34, \mathrm{p}<0.001)$, marital status $(\mathrm{aOR}=0.44, \mathrm{CI} ; 0.25-0.77, \mathrm{p}=0.004)$, and awareness of partner's HIV status $(\mathrm{aOR}=0.52, \mathrm{CI} ; 0.30-0.89, \mathrm{p}=$ 0.018) remained statistically associated with engaging in multiple partnership (Table 5).

Data on condom use in multiple partnerships showed that $(n=55,40.4 \%)$ of participants who had more than one sex partners reported inconsistent condom use. At multiple logistic regressions, consistent condom use in 
Table 5. Multivariate analysis of multiple sex partners and associated factors among ART patients in a clinic in Johannesburg, South Africa.

\begin{tabular}{|c|c|c|c|c|}
\hline & \multicolumn{2}{|c|}{ Number of sexual partners } & \multirow{2}{*}{$\begin{array}{c}\text { Adjusted odds ratios } \\
\text { OR/95\% CI }\end{array}$} & \multirow[t]{2}{*}{ p value } \\
\hline & Single & Multiple & & \\
\hline Female & $162(69.2)$ & $45(33.1)$ & $5.69(3.39-9.57)$ & 0.000 \\
\hline Male & $72(30.8)$ & $91(66.9)$ & & \\
\hline \multicolumn{5}{|l|}{ Employment status } \\
\hline Scholar & $6(2.6)$ & $1(0.7)$ & $1.17(0.72-1.89)$ & 0.509 \\
\hline Unemployed & $84(35.9)$ & $40(29.6)$ & & \\
\hline Employed & $144(61.5)$ & $94(69.6)$ & & \\
\hline \multicolumn{5}{|l|}{ Marital status } \\
\hline Single & $130(55.6)$ & $100(73.5)$ & $0.43(0.24-0.75)$ & 0.003 \\
\hline Married & $104(44.4)$ & $36(26.5)$ & & \\
\hline \multicolumn{5}{|l|}{ Type of partner } \\
\hline Casual & $48(20.5)$ & 46 (33.8) & $0.58(0.33-1.04)$ & 0.068 \\
\hline Steady & $186(79.5)$ & $90(66.2)$ & & \\
\hline \multicolumn{5}{|c|}{ Discuss HIV testing with partner } \\
\hline No & $102(43.6)$ & $72(52.9)$ & $0.81(0.49-1.36)$ & 0.443 \\
\hline Yes & $132(56.4)$ & $64(47.1)$ & & \\
\hline \multicolumn{5}{|c|}{ Know regular sex partners' status } \\
\hline Unaware & $71(30.3)$ & $65(47.8)$ & $0.46(0.24-0.86)$ & 0.016 \\
\hline Aware & $163(69.7)$ & $71(52.2)$ & & \\
\hline \multicolumn{5}{|c|}{ Disclosed HIV status to regular partner } \\
\hline No & 45 (19.6) & $45(33.1)$ & $1.42(0.70-2.87)$ & 0.321 \\
\hline Yes & $184(80.4)$ & 91 (66.9) & & \\
\hline
\end{tabular}

multiple partnerships was associated with marital status (aOR $=3.40, \mathrm{CI} ; 1.06-10.89$, $\mathrm{p}=0.039)$, educational status $(\mathrm{aOR}=1.78, \mathrm{CI} ; 1.02-3.10, \mathrm{p}=0.042)$, and duration of time since diagnosis $(\mathrm{aOR}=2.35, \mathrm{CI} ; 1.27-4.32$, $\mathrm{p}=0.006)$, while gender $(\mathrm{aOR}=0.33$, CI; $0.15-0.71, \mathrm{p}=0.005)$, and age $(\mathrm{aOR}=0.38, \mathrm{CI} ; 0.15-0.99, \mathrm{p}=$ 0.048) were associated with inconsistent condom use.

\section{Discussion}

Although studies report reductions in unprotected sex among HIV-infected persons on ART, the risk of HIV-transmission remains worrying as a number of HIV-infected persons continue to engage in unprotected sex [1]-[4] [6]. The on-goingreports about inconsistent condom use among HIV-infected persons have raised concerns that condom use fatigue may be occurring simultaneously with prolonged life through the use of ART [4] [5] [10]. More so because of the high reported rates of unprotected sex despite the on-going risk reduction counselling linked to ART programs. Of concern is that inconsistent condom use by HIV-infected persons on ART occurred in all types of partners including marriage, casual, steady, and multiple sexual partners [4].

The analysis in this study showed that consistent condom use among HIV-infected persons on ART was generally high, yet a quarter (24.1\%) used condoms in an inconsistent manner. The rates of inconsistent condom use in this study are concerning even though they are lower than those reported in Ethiopia (36.9\%), Uganda (50\% 70\%), Uganda (35\%), India (32\%), and in Kenya (57\%) [3]-[5] [15] [18]. We also found that similar to previous studies; inconsistent condom use was reported regardless of the HIV status of the partner [15] [18] [19] [21]. This finding underlines a real concern of the risk of on-going HIV transmission among partners of known or unknown HIV status of HIV-infected persons on ART [13]. HIV prevention programs need to design appropri- 
ate prevention messages that specifically target HIV positive couples receiving ART [22].

We found that discussing HIV testing with partner, awareness of partner's HIV status, level of education, and duration of time on ART, were independent predictors for consistent condom use with a regular partner. In line with other studies, condom use increased with increasing level of education. Ayiga [4] found that the level of education had the greatest impact on consistent condom use by HIV positive persons in her study. This finding is likely because of the high self-efficacy for condom-use among people who have secondary or tertiary-level education. However, our findings are in contrast to results reported in Tanzania where participants with more than seven years of education were less likely to use condoms consistently [12].

Two thirds (63.2\%) of the participants in this study were aware of their partners' HIV-status. There was a strong association between knowing a partners status and discussion HIV testing with a partner at bivariate analysis ( $<$ 0.001). Dessie et al. [5] found that discussing condom use with a sex partner was associated with consistent condom use. These findings suggest that partner testing in ART programs could protect HIV-uninfected partners at risk for HIV by revealing discordant status, which in turn may increase condom use [18]. We found that awareness of partners' HIV status was the strongest predictor of consistent condom use and our results are in agreement with other studies [12] [18].

Although awareness of partner's HIV status in this study was high, over a third (36.7\%) of the participants were unaware of their partners' HIV status and less likely to use condoms consistently. Similar findings were reported in other studies [1] [10] [17]-[19] [21] [23] [24]. The implication of not knowing partner's HIV status is the possibility of unprotected sex with partners who are HIV negative or whose HIV status is unknown, subsequently, increasing the risk of HIV transmission [18] [19] [25]. In this study, of the 89 participants who engaged in unprotected sex, two thirds (61.8\%) were unaware of their regular partner's HIV status. HIV prevention messages to address the high rates of inconsistent condom use should target individuals who are unaware of their partners' HIV status.

Inquiring about a partner's HIV status has been associated with an increase in the likelihood of negotiating safer sex practices [12]. While lack of knowledge of partners' HIV status sets the stage for HIV transmission to HIV negative partners [1]. In this study, participants who were aware of their partners' HIV status were more likely to be married, living with the partner, have discussed HIV testing with a partner, have longer duration of time since diagnosis, and have more than one sex partners. Since awareness of partners' HIV status is associated with consistent condom, it could be suggested that even in multiple partnerships, awareness of partners' status is protective against HIV transmission. While consistent use of condoms in multiple partnerships is critical in preventing the spread of HIV and re-infection by different strains.

The association between consistent condom use and duration of time on ART has been reported in other studies [13] [22] [26]. We also found that longer ART use was significantly associated with consistent condom use. These findings support the theory that the longer HIV persons have been on treatment, the higher the level of condom use [22]. Longitudinal studies conducted in sub Saharan countries also reported an association between the duration on ART and reductions in sexual risk behaviours including unprotected sex [1]-[4] [6] [7] [10] [27]. However, it is argued that reductions in sexual risk behaviour are not solely attributed to receiving ART, but also to the effectiveness of ART programs. The on-going counselling and HIV prevention messages provided at ART initiation and follow up has contributed to reductions in sexual risk behaviours. Furthermore, it had been shown that when persons receiving ART accept their illness and adjust to being HIV positive, they are likely to modify sexual behaviours [1] [3] [5] [9] [13] [17] [26]. Therefore, strengthening the provision of secondary prevention messages and risk-reduction interventions in ART programs creates an enabling environment for reduction of risky sexual behaviours [13] [22]. Moreover, HIV-infected persons with longer duration on ART might use condoms consistently to protect their sex partners from infection [4] [6]. Our data further point out that the association between longer duration on ART and awareness of partner's HIV status is crucial in the reduction of risky sexual behaviour among HIV-infected persons on ART.

A high proportion (36.8\%) of participants reported multiple sexual partners; this rate is higher than previously reported in South Africa (5.7\%), Botswana (20.6\%), Ethiopia (10\%), and Uganda (18\%) [3]-[5] [28]. This study did not establish the reasons for engaging in multiple partnerships, but male and female participants in a study conducted in Mozambique, believed that social and cultural factors encourage men to have multiple sexual partners [19]. The cultural belief could explain the reason multiple partnerships occurred in all types of partners in this study, even among married couples. Participants who had more than one sex partners were more likely to be male, married, and aware of partner's HIV status. Gender was a strong predictor of engaging in multiple partnerships, 
and men were six times more likely to have more than one sex partners than females. Male gender was also a predictor of multiple partnerships among married couples; married men were more likely to have multiple partnerships than women. Those who were aware of partner's HIV status were less likely to have multiple partners.

In line with previous studies, engaging in multiple partnerships was associated with inconsistent condom use [5] [13] [19] [23] [28]. While gender was not associated with inconsistent condom use with regular partners, in multiple partnerships, gender was a predictor of inconsistent condom use. Men were less likely to use condoms in a consistent manner than females. Similar findings were reported in Kenya [13]. We further found that inconsistent condom use within multiple partnerships varied by other socio-demographic characteristics. Older participants were less likely to use condoms in a consistent manner than their younger counterparts. Similar to factors associated with consistent condoms use with regular partners, participants who had a tertiary or college education and had longer duration since diagnosis, were more likely to use condoms consistently in multiple partnerships. Marital status was a protective factor in multiple partnership; married participants were more likely to use condoms consistently than those who are single. This finding suggests that married persons who engage in multiple partners want to protect their regular partners from HIV infection. This is explained by the strong association between marital status and awareness of partner's HIV status. If engaging multiple partnerships is rooted in cultural beliefs, interventions to promote safe sex should understand the dynamics and the social context of multiple partnerships.

The study is limited by reliance on self-reported data on condom use, multiple sex partnerships, and awareness of partner's HIV status. Although the interviews were conducted by trained researchers who were not part of the clinic staff, recall and social desirability biases may have occurred. In order to minimize the recall bias we chose a 3 month recall period for sexual behaviors. The researchers were also trained to create good relations and help patients in answering questions. This study cannot comment on the reasons for inconsistent condom use and other risky sexual behaviours. Despite these limitations, this study has significant public health relevance and the data could inform intervention strategies to reduce risky sexual behaviour among HIV positive persons on ART.

\section{Conclusions}

In conclusion, we found that awareness of partner's HIV status was a predictor of consistent condom use with regular and multiple partnerships and is a necessary condition for the reduction of risky sexual behaviour. Engaging in risky sexual behaviour occurred in all types of partners and continues to pose a high risk for HIV transmission to seronegative partners and reinfection within sero positive partners. It is therefore, essential that HIV prevention strategies should create an enabling environment for reductions of risky sexual behaviours.

One of the weaknesses of HIV prevention efforts for HIV-infected persons in South Africa, is that prevention messages are provided around HIV-testing and at the time of initiating ART and are seldom repeated during regular contacts for ART follow-up. Therefore, it is important to strengthen the provision of secondary prevention messages and risk-reduction interventions in ART programs. Interventions should take into consideration the cultural and social context of sexual behaviour and condom use of the communities accessing HIV treatment and care.

The provider initiated counselling and testing initiative by the ministry of Health in South Africa provides a window of opportunity to reach HIV positive people with HIV prevention messages and strategies before they are enrolled for ART. Successful provision of ART as a preventive measure depends on substantial and sustained reductions in sexual risk behaviour by HIV-infected persons receiving ART.

\section{Acknowledgements}

The authors acknowledge the staff at the Charlotte Maxeke Hospital ARV clinic for their support and cooperation during the collection of data for this study. We also appreciate the research, Peggy Malebane, for her role in ensuring that the data is collected. We also appreciate the partial funding by the Directorate General for Development Cooperation (DGDC) through the Flemish Interuniversity council (VLIR-UOS). Our greatest appreciation is to the patients who gave their time to participate in this study.

\section{References}

[1] Sarna, A., Luchters, S., Geibel, S., Kaai, S., Munyao, P., et al. (2008) Sexual Risk Behaviour and HAART: A Com- 
parative Study of HIV-Infected Persons on HAART and on Preventive Therapy in Kenya. International Journal of STD \& AIDS, 19, 85-89. http://dx.doi.org/10.1258/ijsa.2007.007097

[2] Yalew, E., Zegeye, D.T. and Meseret, S. (2012) Patterns of Condom Use and Associated Factors among Adult HIV Positive Clients in North Western Ethiopia: A Comparative Cross Sectional Study. BMC Public Health, $12,308$. http://dx.doi.org/10.1186/1471-2458-12-308

[3] Venkatesh, K.K., de Bruyn, G., Lurie, M.N., Mohapi, L., Pronyk, P., et al. (2010) Decreased Sexual Risk Behavior in the Era of HAART among HIV-Infected Urban and Rural South Africans Attending Primary Care Clinics. AIDS (London, England), 24, 2687-2696. http://dx.doi.org/10.1097/QAD.0b013e32833e78d4

[4] Ayiga, N. (2012) Rates and Predictors of Consistent Condom-Use by People Living with HIV/AIDS on Antiretroviral Treatment in Uganda. Journal of Health, Population, and Nutrition, 30, 270-280. http://dx.doi.org/10.3329/jhpn.v30i3.12290

[5] Dessie, Y., Gerbaba, M., Bedru, A. and Davey, G. (2011) Risky Sexual Practices and Related Factors among ART Attendees in Addis Ababa Public Hospitals, Ethiopia: A Cross-Sectional Study. BMC Public Health, 11, 422. http://dx.doi.org/10.1186/1471-2458-11-422

[6] Luchters, S., Sarna, A., Geibel, S., Chersich, M.F., Munyao, P., et al. (2008) Safer Sexual Behaviors after 12 Months of Antiretroviral Treatment in Mombasa, Kenya: A Prospective Cohort. AIDS patient care and STDs, 22, 587-594. http://dx.doi.org/10.1089/apc.2007.0247

[7] Eisele, T.P., Mathews, C., Chopra, M., Lurie, M.N., Brown, L., et al. (2009) Changes in Risk Behavior among HIV-Positive Patients during Their First Year of Antiretroviral Therapy in Cape Town South Africa. AIDS and Behavior, 13, 1097-1105. http://dx.doi.org/10.1007/s10461-008-9473-2

[8] Apondi, R., Bunnell, R., Ekwaru, J.P., Moore, D., Bechange, S., et al. (2011) Sexual Behavior and HIV Transmission Risk of Ugandan Adults Taking Antiretroviral Therapy: 3 Year Follow-Up. AIDS, 25, 1317-1327. http://dx.doi.org/10.1097/QAD.0b013e328347f775

[9] Shafer, L.A., Nsubuga, R.N., White, R., Mayanja, B.N., Chapman, R., et al. (2011) Antiretroviral Therapy and Sexual Behavior in Uganda: A Cohort Study. AIDS, 25, 671-678. http://dx.doi.org/10.1097/QAD.0b013e328341fb18

[10] Wandera, B., Kamya, M.R., Castelnuovo, B., Kiragga, A., Kambugu, A., et al. (1999) Sexual Behaviors over a 3-Year Period among Individuals with Advanced HIV/AIDS Receiving Antiretroviral Therapy in an Urban HIV Clinic in Kampala, Uganda. Journal of Acquired Immune Deficiency Syndromes, 57, 62-68. http://dx.doi.org/10.1097/QAI.0b013e318211b3f2

[11] Kaye, D.K., Kakaire, O., Osinde, M.O., Lule, J.C., and Kakande, N. (2013) The Impact of Highly Active Antiretroviral Therapy on High-Risk Behaviour of HIV-Infected Patients in Sub-Saharan Africa. The Journal of Infection in Developing Countries, 7, 436-447. http://dx.doi.org/10.3855/jidc.2644

[12] Conserve, D., Sevilla, L., Younge, S., Mbwambo, J. and King, G. (2012) Condom Use among HIV-Positive Sexually Active Adults and Partner's HIV Status in Dares Salaam, Tanzania. Journal of Health Care for the Poor and Underserved, 23, 191-203. http://dx.doi.org/10.1353/hpu.2012.0010

[13] Ragnarsson, A., Ekström, A.M., Carter, J., Ilako, F., Lukhwaro, A., et al. (2011) Sexual Risk Taking among Patients on Antiretroviral Therapy in an Urban Informal Settlement in Kenya: A Cross-Sectional Survey. Journal of the International AIDS Society, 14, 20. http://dx.doi.org/10.1186/1758-2652-14-20

[14] Venkatesh, K.K., Srikrishnan, A., Safren, S.A., Triche, E.W., Thamburaj, E., et al. (2011) Sexual Risk Behaviors among HIV-Infected South Indian Couples in the HAART Era: Implications for Reproductive Health and HIV Care Delivery. AIDS Care, 23, 722-733. http://dx.doi.org/10.1080/09540121.2010.525616

[15] Wagner, G.J., Holloway, I., Ghosh-Dastidar, B., Ryan, G. and Kityo, C. (2010) Factors Associated with Condom Use among HIV Clients in Stable Relationships with Partners at Varying Risk for HIV in Uganda. AIDS and Behavior, 14, 1055-1065. http://dx.doi.org/10.1007/s10461-010-9673-4

[16] Gari, T., Habte, D. and Markos, E., (2010) HIV Positive Status Disclosure to Sexual Partner among Women Attending ART Clinic at Hawassa University Referral Hospital, SNNPR, Ethiopia. Ethiopian Journal of Health Development, 24, 87-91. http://dx.doi.org/10.4314/ejhd.v24i1.62940

[17] Mlambo, M. and Peltzer, K. (2011) HIV Sero-Status Disclosure and Sexual Behaviour among HIV Positive Patients Who Are on Antiretroviral Treatment (ART) in Mpumalanga, South Africa. Journal of Human Ecology, 35, 29-41.

[18] Benki-Nugent, S., Chung, M.H., Ackers, M., Richardson, B.A., McGrath, C.J., et al. (2011) Knowing a Sexual Partner Is HIV-1-Uninfected Is Associated With Higher Condom Use among HIV-1-Infected Adults in Kenya. Sexually transmitted diseases, 38, 808-810. http://dx.doi.org/10.1097/OLQ.0b013e31821c3713

[19] Pearson, C.R., Cassels, S., Kurth, A.E., Montoya, P. and Micek, M.A. (2011) Change in Sexual Activity 12 Months after ART Initiation among HIV-Positive Mozambicans. AIDS and Behavior, 15, 778-787. http://dx.doi.org/10.1007/s10461-010-9852-3 
[20] StataCorp (2007) Stata Statistical Software. Release 10. TX: StataCorp LP.

[21] Bajunirwe, F., Bangsberg, D.R. and Sethi, A.K. (2013) Alcohol Use and HIV Serostatus of Partner Predict High-Risk Sexual Behavior among Patients Receiving Antiretroviral Therapy in South Western Uganda. BMC Public Health, 13, 430. http://dx.doi.org/10.1186/1471-2458-13-430

[22] Akinyemi, J.O., Awolude, O.A., Adewole, I.F. and Kanki, P.J. (2010) Condom Use among Antiretroviral Therapy Patients in Ibadan, Nigeria. The Journal of Infection in Developing Countries, 4, 495-502. http://dx.doi.org/10.3855/jidc.732

[23] Osinde, M., Kaye, D. and Kakaire, O. (2011) Sexual Behaviour and HIV Sero-Discordance among HIV Patients Receiving HAART in Rural Uganda. Journal of Obstetrics \& Gynaecology, 31, 436-440. http://dx.doi.org/10.3109/01443615.2011.578228

[24] Simbayi, L.C., Kalichman, S.C., Strebel, A., Cloete, A. and Henda, N. (2007) Disclosure of HIV Status to Sex Partners and Sexual Risk Behaviours among HIV-Positive Men and Women, Cape Town, South Africa. Sexually Transmitted Infections, 83, 29-34. http://dx.doi.org/10.1136/sti.2006.019893

[25] Deribe, K., Woldemichael, K., Wondafrash, M., Haile, A. and Amberbir, A. (2008) High-Risk Behaviours and Associated Factors among HIV-Positive Individuals in Clinical Care in Southwest Ethiopia. Tropical Doctor, 38, 237-239. http://dx.doi.org/10.1258/td.2008.070405

[26] Chakrapani, V., Newman, P.A., Shunmugam, M. and Dubrow, R. (2010) Prevalence and Contexts of Inconsistent Condom Use among Heterosexual Men and Women Living with HIV in India: Implications for Prevention. AIDS Patient Care and STDs, 24, 49-58. http://dx.doi.org/10.1089/apc.2009.0214

[27] Bunnell, R., Ekwaru, J.P., Solberg, P., Wamai, N., Bikaako-Kajura, W., et al. (2006) Changes in Sexual Behavior and Risk of HIV Transmission after Antiretroviral Therapy and Prevention Interventions in Rural Uganda. AIDS, 20, 85-92. http://dx.doi.org/10.1097/01.aids.0000196566.40702.28

[28] Kalichman, S.C., Ntseane, D., Nthomang, K., Segwabe, M. and Phorano, O. (2007) Recent Multiple Sexual Partners and HIV Transmission Risks among People Living with HIV/AIDS in Botswana. Sexually Transmitted Infections, 83, 371-375. http://dx.doi.org/10.1136/sti.2006.023630 